\title{
ChIP on Chip: surprising results are often artifacts
}

\author{
Torsten Waldminghaus and Kirsten Skarstad*
}

\begin{abstract}
Background: The method of chromatin immunoprecipitation combined with microarrays (ChIP-Chip) is a powerful tool for genome-wide analysis of protein binding. However, a high background signal is a common phenomenon.

Results: Reinvestigation of the chromatin immunoprecipitation procedure led us to discover four causes of high background: i) non-unique sequences, ii) incomplete reversion of crosslinks, iii) retention of protein in spin-columns and iv) insufficient RNase treatment. The chromatin immunoprecipitation method was modified and applied to analyze genome-wide binding of SeqA and $\mathrm{O}^{32}$ in Escherichia coli.

Conclusions: False positive findings originating from these shortcomings of the method could explain surprising and contradictory findings in published ChIP-Chip studies. We present a modified chromatin immunoprecipitation method greatly reducing the background signal.
\end{abstract}

\section{Background}

Chromatin immunoprecipitation coupled with microarray analysis (ChIP-Chip) has become a widely used method for genome-wide localization of protein-DNA interactions [1]. Protocols have been established for different organisms with surprisingly little variation [2-5]. The first step in the ChIP-Chip procedure is to fix protein-DNA interactions in living cells by chemical crosslinking (Fig. 1). The crosslinker must be small to diffuse fast into the cells. In practice, formaldehyde is used in most ChIP-Chip experiments. After cell lysis the DNA is fragmented by sonication. This extract is then subjected to immunoprecipitation (IP) with a specific antibody against the protein of interest. DNA bound by the protein will be coprecipitated and enriched compared to DNA not bound by the respective protein. To facilitate immunoprecipitation and subsequent washing, antibodies are usually coupled to either agarose- or magnetic beads via protein A or G. After reversion of crosslinking the DNA is purified by phenol extraction or commercial PCR cleanup kits. Often, an amplification step is included after DNA purification. Two different fluorescence labels are used to label the IP DNA and a hybridization control DNA, respectively. Usually total DNA before IP (input DNA) is used as hybridization control. The two differen-

\footnotetext{
* Correspondence: kirsten.skarstad@rr-research.no

1 Department of Cell Biology, Institute for Cancer Research, The Norwegian Radium Hospital, Oslo University Hospital and University of Oslo, 0310 Oslo, Norway

Full list of author information is available at the end of the article
}

tially labeled DNAs are hybridized to the same microarray and the difference in fluorescence intensity gives a measure of the enrichment.

We set out to investigate the genome-wide binding of the sequestration protein SeqA in E. coli [6]. This task can be considered especially challenging because SeqA has been shown to bind selectively to hemimethylated GATC sites [7]. Although there are about 20.000 GATCs around the Escherichia coli chromosome only about $2 \%$ will be hemimethylated in unsynchronized cells [8]. Such cell-tocell variation increases the amount of cell material needed and therefore potentially the level of background signals. In fact, we found that application of a published ChIP-Chip method produced a background signal exceeding the specific signal. However, we were able to reduce the background significantly by modifying the protocol. The new protocol allowed us to uncover the genome-wide binding of SeqA and to reinvestigate $\sigma^{32}$ binding to the E. coli chromosome.

\section{Results \\ High background signal in ChIP-Chip experiments}

To investigate the genome-wide binding pattern of the sequestration protein SeqA in Escherichia coli we applied the ChIP-Chip method as described [3]. Cells were grown in LB medium, crosslinked with formaldehyde and sonicated to break down DNA to fragments of approximately 500 bps. The IP was done in parallel with antibodies against SeqA and, as a control, RNA polymerase subunit 


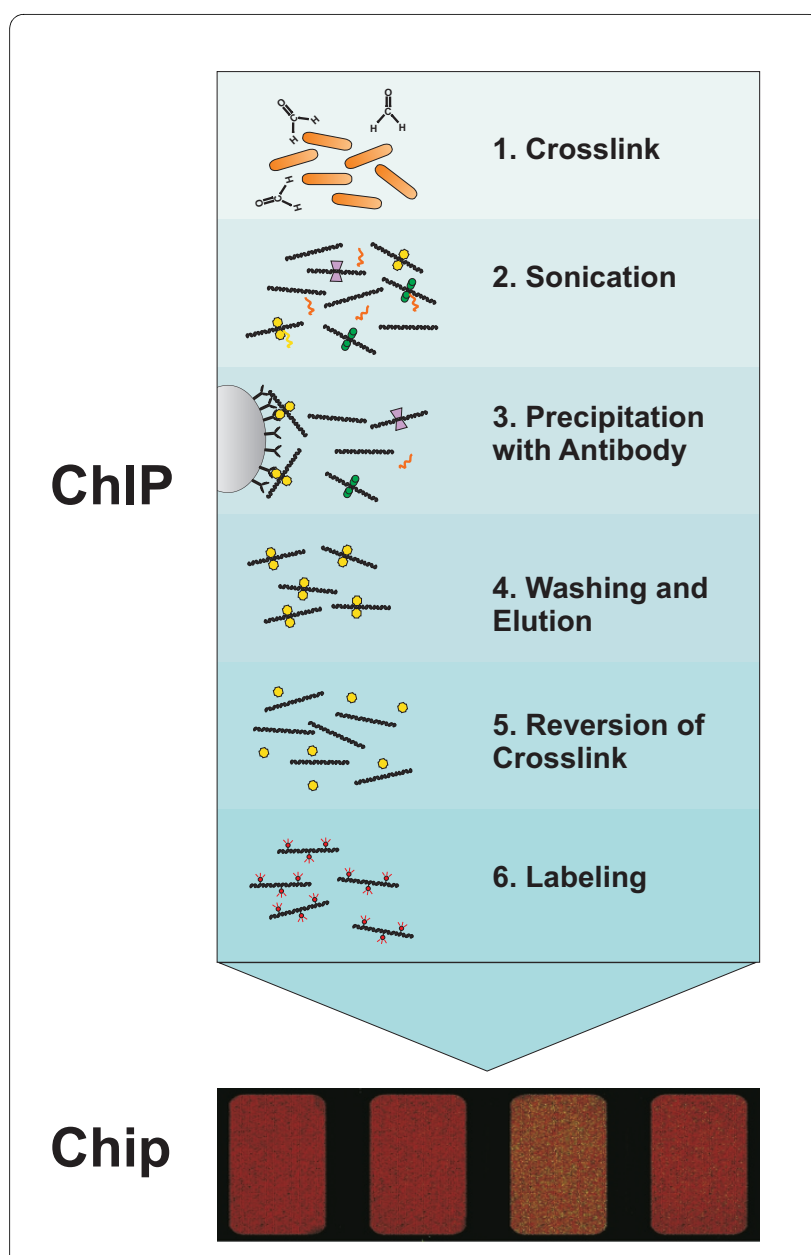

Figure 1 Schematic outline of the ChIP-Chip method. See text for detailed description.

$\beta$. After reversion of crosslinking the DNA of the ChIP sample and the input DNA was differentially labeled and hybridized to a whole-genome microarray. Plotting of the ChIP signal against the genomic position revealed a great number of distinct peaks (Fig. 2). Surprisingly the binding patterns of SeqA and RNA polymerase turned out to be essentially identical (Fig. 2, compare red and blue). The overlap of the highest ChIP signals was $>80 \%$ (Fig. 3A). A difference could only be seen when SeqA and RNA polymerase signals were grouped by the number of SeqA recognition sequences in the region of the corresponding probes (Fig. 2B-C). While a slight correlation between the SeqA ChIP signal and the number of GATC sites was observed at numbers of sites above 5 , this was not the case for the RNA polymerase ChIP-Chip. This indicates that a specific SeqA signal is overlayed by a strong RNA polymerase-like signal in the SeqA ChIP-Chip experiment.

To estimate the degree of background signal in the SeqA ChIP-Chip we repeated the experiment using a
SeqA deletion strain. All signals detected with such a setup should be non-specific, since no SeqA protein will be present in the cell extract. The genome-wide pattern of SeqA ChIP signal in the $\Delta s e q A$ cells showed enrichment at various regions also enriched in the $w t$ cells (Fig. 4A). As expected, the former lacked the slight correlation of the ChIP signal with the local GATC number (Fig. 4B). This demonstrates that the method gave an enormous amount of background signal, exceeding the specific SeqA signal in the $w t$ ChIP-Chip. Note that this background signal is not a variation of single probe intensities. It is instead the appearance of high signals in neighboring probes which is typical for a specific binding detected by ChIP-Chip.

We set out to identify steps in the protocol where DNA regions giving a high background signal on the microarray behave differently compared to regions giving no background. Quantitative PCR (qPCR) was performed with the rpsD region which gave a high background signal on the microarray and $u v r D$ which gave a low background signal (both are marked in Fig. 2). Washing turned out to be one critical step. The rpsD DNA was more than five-fold enriched when a spin-column was used to wash the precipitated fragments bound to agarose beads compared to when the same beads were washed without column (Fig. 5A; see materials and methods for details). Two-fold enrichment was detected for the $u v r D$ region.

The background signal we observed seemed to correspond to highly transcribed regions, i.e. DNA with many RNA polymerase molecules bound (Fig. 2). Protein-rich DNA is segregated into the organic phase during phenolchloroform extraction of crosslinked DNA [9]. However, this phenomenon should not have affected a ChIP-Chip experiment, because the crosslinking is reversed before extraction is performed. The appearance of protein-rich gene regions as background might indicate an incomplete reversion of crosslinking at these sites. To clarify this question we compared DNA that was crosslinked and reversed with DNA that was not crosslinked. (Fig. 5B; see materials and methods for details). If the reversion of the crosslinking in this protocol is complete one would expect the two signals to be the same. This was indeed the case for the $u v r D$ region. However, the rpsD DNA was more than seven-fold reduced in the crosslinked-reversed sample compared to the non-crosslinked DNA. To analyze the effect of crosslinking and reversion on a global scale we differentially labeled the DNA and applied it to a microarray. Ratios of the crosslinked-reversed versus the non-crosslinked DNA are shown in Fig. 5C (blue signal). The results show that the same regions that gave a high background signal in the SeqA ChIP-Chip yielded a reduced signal if the DNA is crosslinked and reversed (Fig. 5C; compare blue and red signal, Fig. 3D-E). 


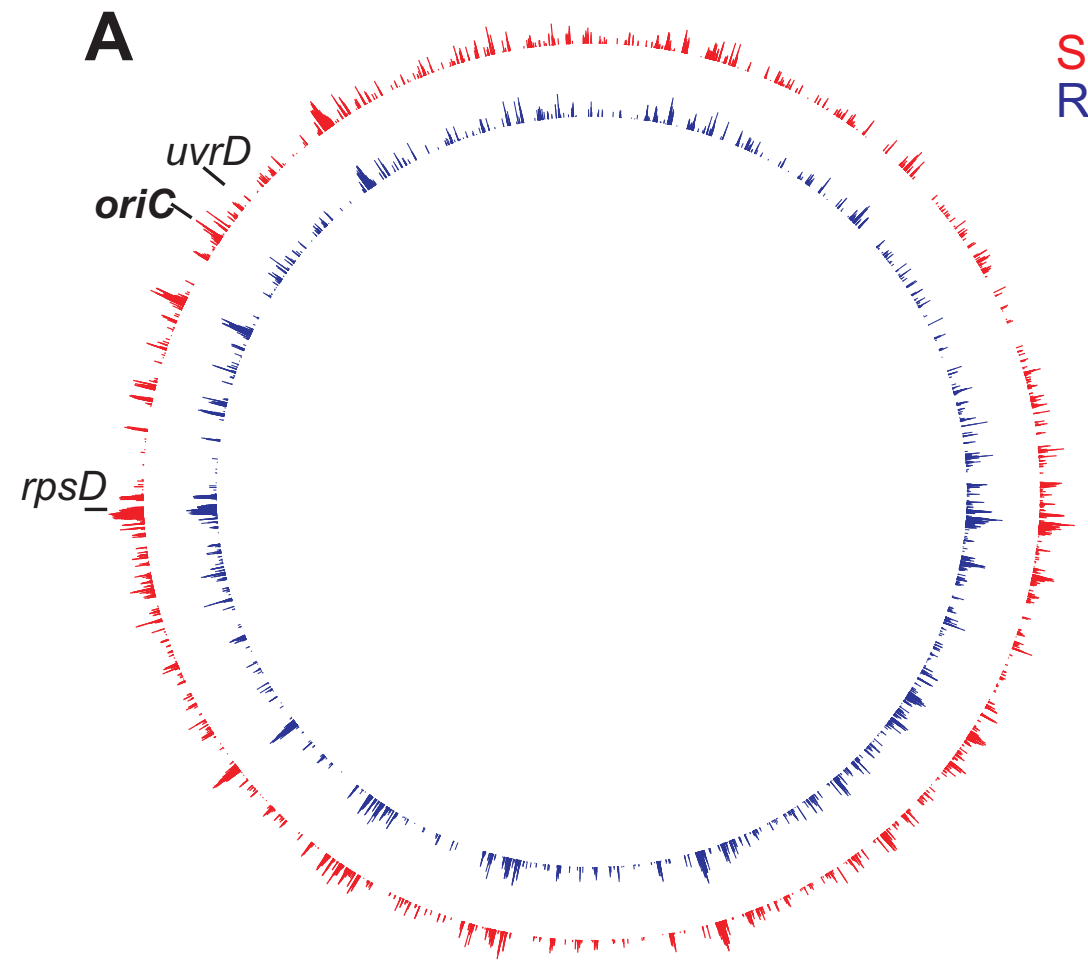

SeqA ChIP-Chip
RNAP ChIP-Chip

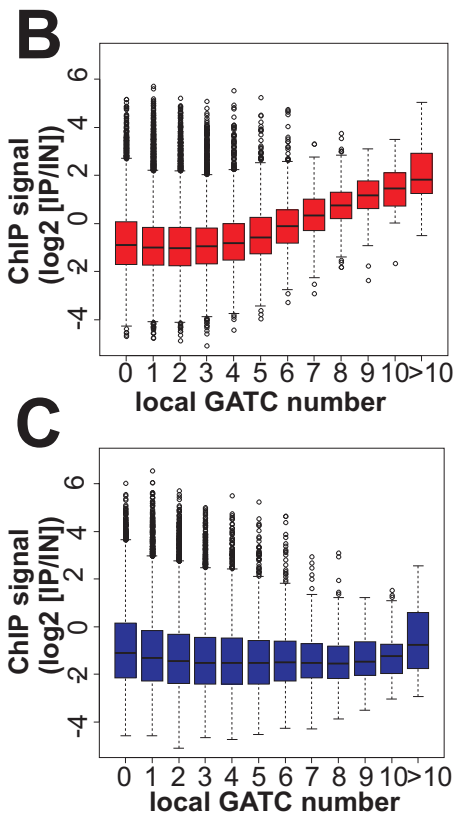

Figure 2 Similar ChIP signal with SeqA and RNA polymerase antibody. A Whole genome plot of RNAP and SeqA ChIP signal (log 2 ratios of ChIP DNA/input DNA, see experimental procedures for details). B-C Correlation of ChIP signal with number of GATC sites. Probes were grouped according to the number of GATC sites in a region of 500 bp surrounding the probe middle position and the corresponding $\log _{2}$ ratios of ChIP DNA/input DNA are given as boxplots for SeqA (B) and RNA polymerase (C).

A

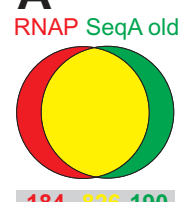

B

RNAP

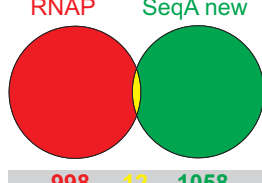

D

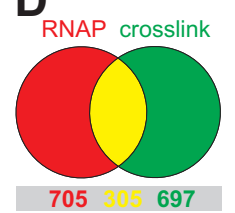

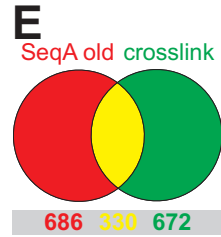

$\mathbf{F}_{\mathrm{s}}$

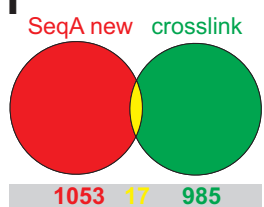

Figure 3 Overlap analysis of ChIP-Chip experiments. For each ChIP data set a cut-off was chosen to select $\sim 1000$ probes with the highest ChIP signal (or the lowest signal for the crosslinking experiment). The overlap (yellow) shows how often the signal is beyond this cut-off at similar positions in the two compared data sets (red and green). Corresponding numbers of probes are given below the Venn diagrams.

We tested if variations of conditions influence the efficiency of crosslink reversion. Crosslinked DNA was reversed at different temperatures and with or without proteinase K (Table 1). Resulting DNA was analyzed by qPCR with $u v r D$ and $r p s D$ primers as above and compared to non-crosslinked DNA. As above, the $u v r D$ control DNA was not changed much by crosslinking and reversion while the rpsD region was depleted. Notably, the level of depletion was similar for all investigated conditions. We conclude that chromosomal regions can be crosslinked to a degree which is not reversible and the respective DNA will be lost for downstream analysis.

\section{Modification of the ChIP-Chip procedure allows genome-} wide analysis of SeqA binding

Considering the identified weaknesses of the ChIP-Chip protocol it was possible to make appropriate modifications (see material and methods for details). The first change was the omission of spin-columns in the washing of agarose beads. Second, the input DNA was taken from the supernatant resulting from centrifugation of the immunoprecipitated chromatin beads. In addition, we included RNase digestion of immunoprecipitated DNA 


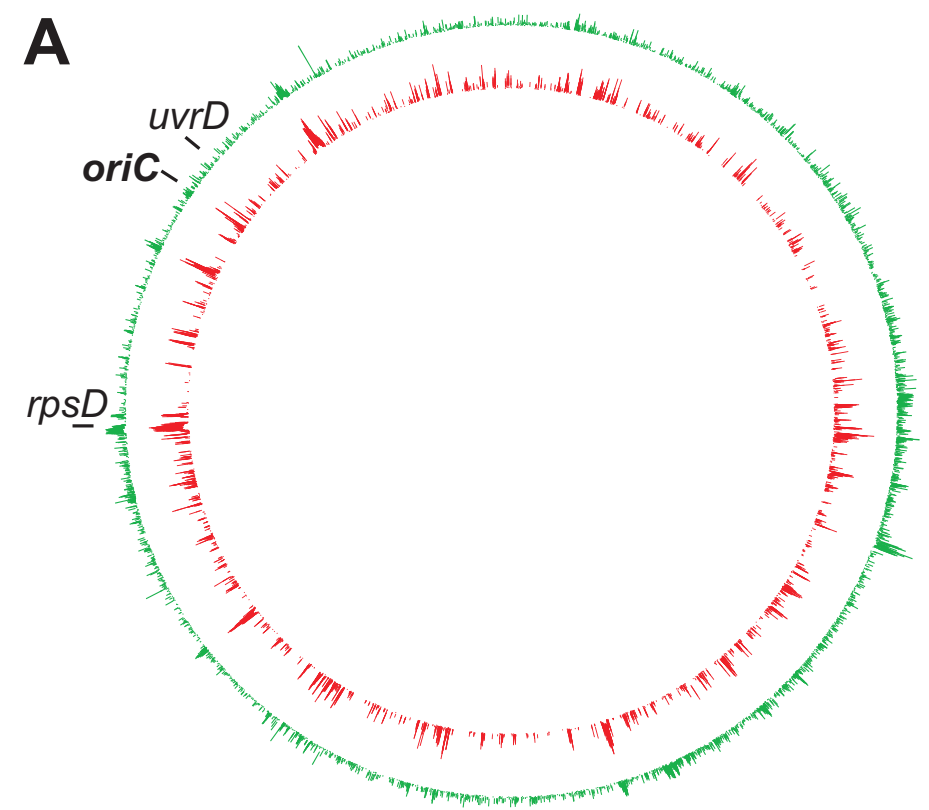

\section{$\Delta$ seqA SeqA ChIP-Chip wt SeqA ChIP-Chip}

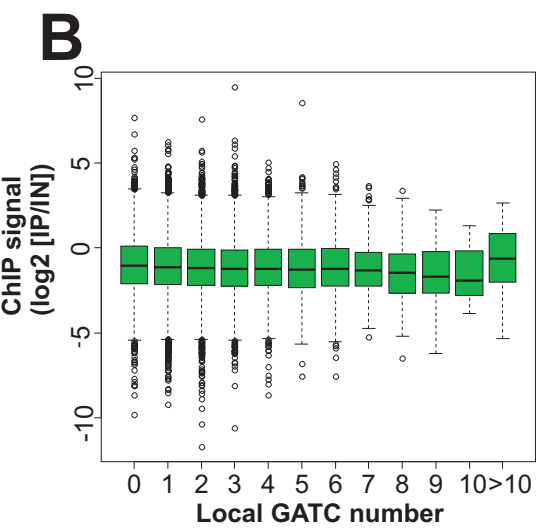

Figure 4 Comparison of SeqA Chip-Chip with wt and $\triangle$ seqA E. coli reveals high background. A Whole genome plot of SeqA ChIP signal for $E$. coli $\triangle$ seqA (green) and E. coliwt (red; as in Fig. 2) B Correlation of ChIP signal with number of GATC sites. Probes were grouped according to the number of GATC sites in a region of 500 bp surrounding the probe middle position and the corresponding ChIP signals are given as boxplots.

and excluded signals originating from microarray-probes to non-unique sequences during data analysis. The reasoning behind the latter two will be described in detail below.

To test the new method we applied it to a cell extract of a seqA deletion strain using antiserum against SeqA (Fig. 6). As described above this should not give a specific ChIP signal and should therefore allow judgment of the level of background signal. Although some background was produced by the new method it was greatly reduced compared to the unmodified method (Fig. 6, compare blue to red). For the rpsD gene region the ChIP signal was reduced about 30 -fold (Fig. 6B).

As a next step we used the new method to detect SeqA binding in $w t E$. coli cells. We found a distinct binding pattern with the highest peak at the origin of replication and very low SeqA binding in the terminus region of the chromosome (Fig. 7). The pattern differed greatly from that detected with the unmodified ChIP-Chip method (Fig. 7, compare red to grey, $3 \mathrm{~B}-\mathrm{C}$ ). Only minimal overlap with the crosslinking background was observed indicating significant reduction of background signals (Fig. 3, compare D-E with F).

To put the results in a biological context we calculated the SeqA binding signal for a 60.000 bp moving window (Fig. 7, inner ring). The reasoning behind this is that SeqA has been shown to bind specifically to hemimethy- lated DNA "trailing" the replication fork. We estimated the stretch of hemimethylated DNA following the replication fork to be $60.000 \mathrm{bp}$ (based on a replication speed of $1000 \mathrm{bp} / \mathrm{sec}$ and an average hemimethylation time of 1 min). The result shows that SeqA binding is not evenly distributed over the chromosome. Instead there are regions with strong binding, such as the origin of replication (oriC) and areas with low binding, such as to the left and right of oriC (Fig. 7). The most extended area with low SeqA binding is about one-fourth of the chromosome around the replication terminus with distinct borders rather than smooth transitions to the neighboring high SeqA binding regions. A clear correlation was observed between the number of GATC sites in the probe region and the corresponding ChIP signal (Fig. 7B). In summary, we have shown that the revised ChIP-Chip protocol can be successfully used to gain insight into the challenging question of chromosome-wide SeqA binding in E. coli.

\section{Reinvestigation of $\sigma^{32}$ binding to the E. coli genome}

Given the enormous background signal produced by the original ChIP-Chip method initially used in this study we considered it likely that published results based on this method would contain many false positives. To examine this experimentally we used our modified ChIP-Chip protocol to reinvestigate binding of the heat shock sigma factor $\sigma^{32}$ to the $E$. coli genome [10]. In the published 
A

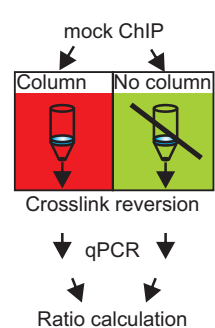

B

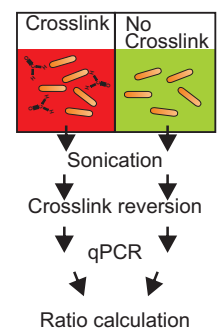

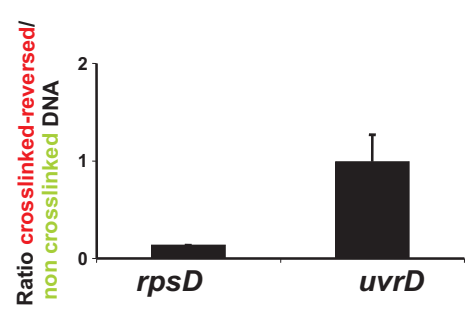

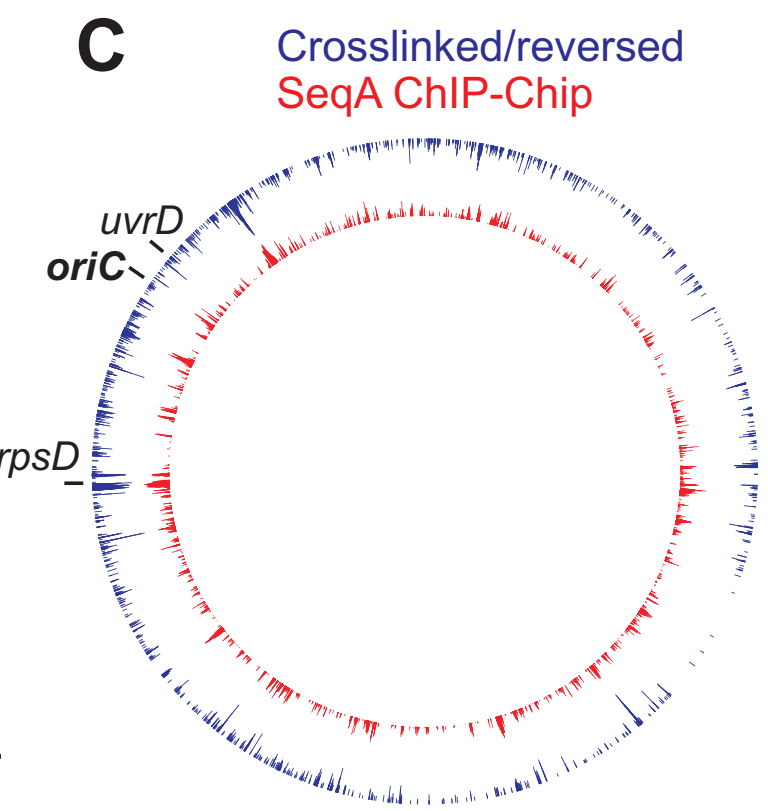

Figure 5 Detection of critical steps in the ChIP-Chip protocol. A Ratios of ChIP DNA purified with spin column versus column free purified DNA detected by qPCR for the indicated gene regions. $\mathbf{B}$ qPCR ratios of crosslinked-reversed versus non crosslinked DNA for indicated gene regions. $\mathbf{C}$ Crosslinked-reversed versus non crosslinked DNA as shown in B was differentially labeled and hybridized to a microarray. Log $_{2}$ ratios are shown in blue (only values below -0.5) in comparison to the SeqA ChIP signal (from Fig. 2).

study many novel $\sigma^{32}$ binding sites were described. Using a specific antibody we precipitated $\sigma^{32}$-bound DNA from lysates of cells before and $5 \mathrm{~min}$ after heat shock. Of the $38 \sigma^{32-t a r g e t s}$ found by Wade et al. and by others in studies using alternative methods, we detected 34 (Table 2). In contrast, out of the 49 targets found exclusively in the Wade et al. ChIP-Chip study, just seven appeared in our results (Table 3 ). Six potential targets were detected that were not found by Wade et al., including the gene $\operatorname{dgs}_{s} A$, also described by others (Table 4)[11]. Since application of our modified method excludes most $\sigma^{32}$-targets described solely in the published ChIP-Chip study we consider it likely that these are in fact false positives (see discussion).
Limited RNase treatment is an additional source of false positives in ChIP-Chip studies

The $\sigma^{32}$ ChIP-Chip was used to investigate additional sources of false positive findings, such as the duration of RNase incubation of immunoprecipitated complexes. While some published ChIP-Chip protocols include an RNase digestion step others do not. We used an extended RNase incubation at $42^{\circ} \mathrm{C}$ for at least $90 \mathrm{~min}$ in our modified ChIP-Chip method. To examine the effect of limited RNA digestion we shortened the incubation to $30 \mathrm{~min}$ with an otherwise unchanged protocol (Fig. 8A). The shortened RNase incubation increased the unspecific background signal drastically compared to the two experiments with longer RNA digestion. Some false positive

Table 1: qPCR ratios of crosslinked-reversed versus non crosslinked DNA

\begin{tabular}{|c|c|c|}
\hline Crosslink reversion ${ }^{b}$ & uvrD (control) & rpsD \\
\hline $37^{\circ} \mathrm{C}$ proteinase $\mathrm{K}$ & $0.36 \pm 0.07$ & $\mathbf{0 . 0 3} \pm 0.01$ \\
\hline $42 / 65^{\circ} \mathrm{C}$ proteinase $\mathrm{K}$ & $\mathbf{0 . 5 9} \pm 0.25$ & $\mathbf{0 . 0 3} \pm 0.01$ \\
\hline $65^{\circ} \mathrm{Co.n}$ & $\mathbf{0 . 4 7} \pm 0.12$ & $\mathbf{0 . 0 3} \pm 0.01$ \\
\hline $100^{\circ} \mathrm{C} 10 \mathrm{~min}$ & $1.03 \pm 0.44$ & $\mathbf{0 . 0 4} \pm 0.02$ \\
\hline
\end{tabular}

aRatios were calculated based on triplicate qPCR values for two independent cultures with the indicated standard deviation.

bShort description of the crosslink reversion method. See method section for details. 


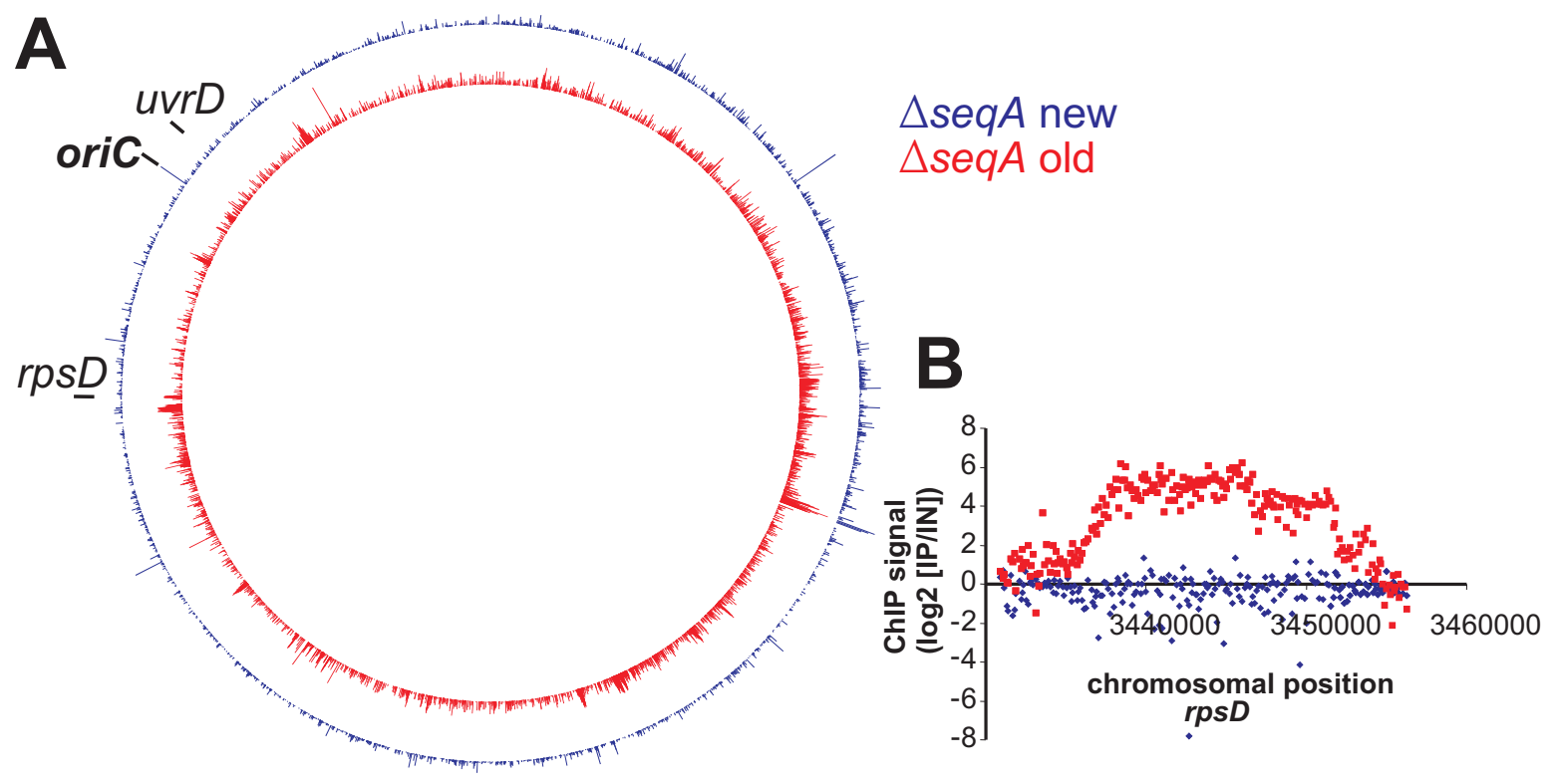

Figure 6 Comparison of background signal with old and modified ChIP-Chip protocol using SeqA antiserum for immunoprecipitation of a $\Delta$ seqA extract. A ChIP signal of the new method (blue) and the old (red). B ChIP signal of SeqA ChIP-Chip of $\triangle$ segA for the genomic region of rpsD. Colors are as in $\mathrm{A}$.
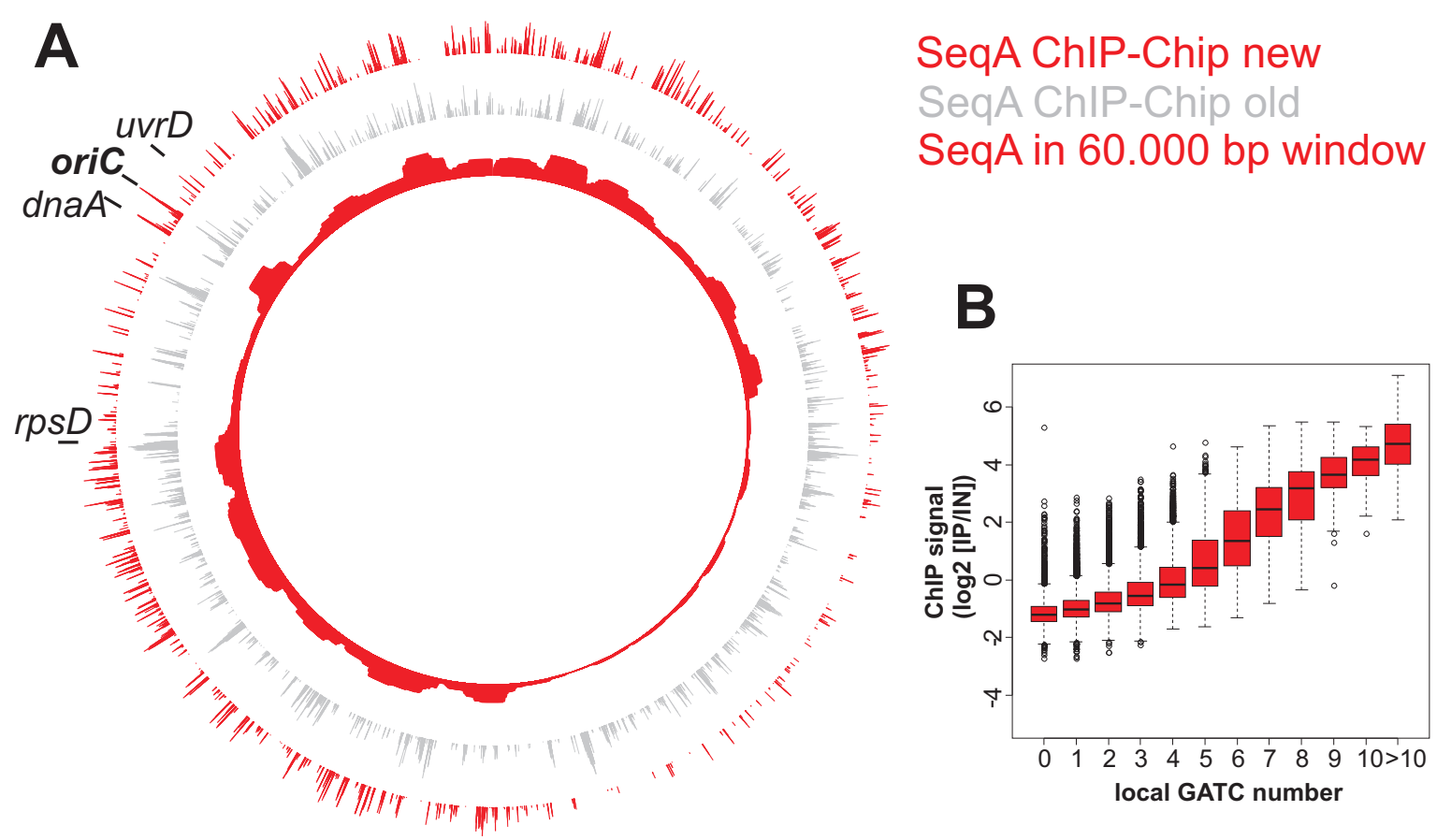

Figure 7 SeqA binding to the $\boldsymbol{E}$. coli chromosome. A Whole genome plot of the SeqA ChIP signal with the modified method (outer red circle) in comparison to the SeqA ChIP signal resulting from old method (grey, compare fig. 2). The inner red circle is the sum of SegA ChIP signals in windows of 60.000 bp (only positive values were included). B Correlation of SeqA ChIP signal with number of GATC sites per 500 bp (see legend to Fig. 2). 
Table 2: Target detection for previously reported $\boldsymbol{\sigma}^{32}$-sites ${ }^{\mathrm{a}}$

\begin{tabular}{|c|c|c|}
\hline Genomic positionb & Targetc & ChIP signald \\
\hline 12153 & dnaK & 2.9 \\
\hline 63524 & hepA & 1.1 \\
\hline 231081 & yafD & 1.2 \\
\hline 415363 & $s b c D$ & 1.3 \\
\hline 455839 & $c l p P$ & 2.0 \\
\hline 458088 & Ion & 2.5 \\
\hline 494367 & htpG & 2.8 \\
\hline 517509 & $y b b N$ & 2.2 \\
\hline 661879 & ybeD & 2.4 \\
\hline 692735 & ybez & 2.5 \\
\hline 921161 & $\operatorname{mac} B$ & 2.1 \\
\hline 1027921 & yccV(hspQ) & 2.0 \\
\hline 1120264 & yceP(dinl) & 2.1 \\
\hline 1173268 & $m f d$ & - \\
\hline 1189625 & phoP & - \\
\hline 1329105 & topA & 2.4 \\
\hline 1338173 & ycis & 2.1 \\
\hline 1382156 & $y c j x$ & 2.9 \\
\hline 1441543 & $\operatorname{ldh} A$ & - \\
\hline 1744259 & ydhQ & 1.4 \\
\hline 1860640 & gapA & 2.1 \\
\hline 1910677 & htpX & 1.6 \\
\hline 2732265 & clpB & 2.2 \\
\hline 2748779 & grpE & 2.3 \\
\hline 2925909 & sdaC & 1.1 \\
\hline 3210766 & rpoD & 1.7 \\
\hline 3325757 & $f t s J$ & 2.2 \\
\hline 3437596 & $y h d N$ & 1.3 \\
\hline 3472778 & rpsL (yheL) & 2.3 \\
\hline 3527175 & yrfG & 2.7 \\
\hline 3643241 & prIC & 2.4 \\
\hline 3865515 & ibpA & 2.4 \\
\hline 3878830 & recF & - \\
\hline 4120359 & $h s / V$ & 2.5 \\
\hline 4366663 & fxsA & 2.4 \\
\hline 4368634 & groE(gros) & 2.2 \\
\hline 4397495 & $\operatorname{mia} A$ & 2.1 \\
\hline 4429090 & сусA & 0.6 \\
\hline
\end{tabular}

a Targets listed were found in a previous ChIP-Chip study [10] and in studies using alternative methods $[11,19]$.

bChromosomal position as middle of two microarray probes. For targets not detected in this study the genomic position described by Wade et al., 2006 are given.

'Names of target genes with synonyms in brackets. Targets detected in this study are in bold.

d Mean $\sigma^{32} \log _{2}$ ratio (IP/IN) of two probes for detected targets at the indicated genomic position (see experimental procedures for details).
Table 3: Target detection for $\sigma^{32}$-sites found only by Wade et al., 2006a

\begin{tabular}{|c|c|c|}
\hline Genomic positionb & Targetc & ChIP signald \\
\hline 22199 & iles & - \\
\hline 239254 & yafU & 1.6 \\
\hline 516521 & $y b b M$ & - \\
\hline 705196 & $g \ln S$ & - \\
\hline 918375 & $y b j x$ & - \\
\hline 1063460 & yccE & - \\
\hline 1213931 & $y c g F$ & - \\
\hline 1247539 & dhaM & - \\
\hline 1293531 & $t d k / y c h G$ & - \\
\hline 1579583 & ydeN & - \\
\hline 1581861 & ydeO & - \\
\hline 1584068 & ydeP & - \\
\hline 1609353 & yneF & - \\
\hline 1624219 & $d c p$ & - \\
\hline 1710454 & $y d g R$ & - \\
\hline 1789863 & ydiv & - \\
\hline 1894985 & $s d a A$ & 0.7 \\
\hline 2166182 & b2084(yegR) & - \\
\hline 2209265 & yehR & - \\
\hline 2217821 & yehz & - \\
\hline 2236301 & $m g / A$ & - \\
\hline 2288414 & narP & - \\
\hline 2319337 & atos & - \\
\hline 2385514 & $y f b M / y f b n$ & 1.0 \\
\hline 2520600 & $x a p R$ & - \\
\hline 2533473 & $\mathrm{crr}$ & - \\
\hline 2735126 & yfiO & - \\
\hline 2762841 & $y f j L$ & - \\
\hline 2764390 & $y f j N(r n \mid A)$ & - \\
\hline 2769847 & $y f j U$ & 0.9 \\
\hline 2771222 & $b 2641$ & - \\
\hline 2780322 & ypjA & 1.3 \\
\hline 2798757 & $n r d H$ & - \\
\hline 2879078 & $y g c l$ & - \\
\hline 2923838 & yqcD(queF) & - \\
\hline 3117399 & yghJ & - \\
\hline 3427148 & $y r d A$ & - \\
\hline 3543459 & $y h g H(g n t X)$ & - \\
\hline 3725552 & yiaA & - \\
\hline 3764283 & yibA & - \\
\hline 3766465 & yibG & - \\
\hline 4124864 & rpmE & - \\
\hline 4359431 & cadC & - \\
\hline 4435901 & $y t f l$ & - \\
\hline 4465355 & treR & - \\
\hline 4482322 & holc & - \\
\hline
\end{tabular}


Table 3: Target detection for $\boldsymbol{\sigma}^{32}$-sites found only by Wade et al., 2006 (Continued)

\begin{tabular}{lcc}
\hline 4524170 & yjhl & 1.2 \\
4539344 & fimB & 0.8 \\
4570170 & yjiT & - \\
\hline a Targets listed were found only in a previous ChIP-Chip study [10] \\
b Chromosomal position as middle of two microarray probes. For \\
targets not detected in this study the genomic position described by \\
Wade et al., 2006 are given. \\
c Names of target genes with synonyms in brackets. Targets detected \\
in this study are in bold. \\
d Mean $\sigma^{32} \log _{2}$ ratio (IP/IN) of two probes for detected targets at the \\
indicated genomic position (see experimental procedures for \\
details).
\end{tabular}

$\sigma^{32}$-targets of the published ChIP-Chip study described above might originate from RNA, since the method used lacks an RNase step. Accordingly, we observed a much higher signal with shorter compared to extended RNase treatment for some of the false positive $\sigma^{32}$-targets (for example $y g h J$, Fig. 8B).

\section{Non-unique sequences can cause false positives in ChIP- Chip analysis}

One important source of false positive findings in ChIPChip studies is the inclusion of non-unique sequences. For the 40.000 probes on the microarray used in this study we examined the number of complementary sequences on the $E$. coli chromosome. 889 probes were found to match multiple loci on the chromosome, the numbers ranging from 2 to 11 (data not shown). Note that signals obtained with these probes and the surrounding probes were routinely excluded from all results shown above as mentioned. However, to investigate the effect of these non-unique probes we reanalyzed the $\sigma^{32}$-ChIPChip experiment of $30^{\circ} \mathrm{C}$ cells described above including the non-unique sequences (Fig. 8C). Some of these probes gave an elevated ChIP signal. Consequently, six new peaks were detected by our search algorithm in addition to the 15 peaks detected before (Fig. 8C). Also the published $\sigma^{32}$-study includes two target sites in nonunique sequence regions. These are the $y i b A$ promoter close to the rhs $A$ gene and the $y r d A$ promoter downstream of the ribosomal RNA gene $r r s D$. In summary, our data demonstrate the potential of non-unique sequences to cause false-positive findings in ChIP-Chip studies.

\section{Discussion}

Multiple sources of false positives in ChIP-Chip studies

Here we present four sources of high background signals that caused false positive target site detection in our experiments as well as in many published studies. In the following we discuss how this unspecific background might occur. The first two problems, namely the selective
Table 4: $\sigma^{32}$ target candidates not detected in Wade et al.

\begin{tabular}{ccc}
\hline Genomic position $^{\mathbf{a}}$ & Target $^{\mathbf{b}}$ & ChIP signal \\
\hline 354094 & $\operatorname{codB}$ & 1.9 \\
1660133 & ynfF & 0.5 \\
1666656 & $\boldsymbol{d g s A}$ & 1.5 \\
1798225 & $\mathrm{rpml}$ & 0.5 \\
2276466 & yejG & 0.6 \\
4148429 & $p p c$ & 0.8 \\
\hline
\end{tabular}

a Chromosomal position as middle of two microarray probes.

b Names of target genes. Known $\sigma^{32}$-targets are in bold according to (Nonaka et al., 2006; Zhao et al., 2005).

c Mean $\sigma^{32} \log _{2}$ ratio (IP/IN) of two probes for detected targets at the indicated genomic position (see experimental procedures for details).

enrichment of some DNA fragments during spin-column washing and the variability in reversion of crosslinking, might actually be due to the same circumstance. Both affected chromosomal regions with high transcription activity, such as the ribosomal protein gene $\operatorname{rps} D$ (Fig. 5). In such regions crosslinking of RNA polymerase, DNA and transcribed mRNA will form large complexes. Concerning the washing of immunoprecipitated DNA with spin-columns it is easy to imagine that such highly crosslinked fragments could be trapped in the column matrix. A release of these bound complexes in the elution step would explain the enrichment of protein-rich DNA through washing with spin-columns. This would be limited to the IP DNA in a ChIP experiment because usually no beads are used to purify the input DNA. The logical improvement of the protocol in this case was to wash the immunoprecipitated DNA without spin-columns. Another possibility would be to use systems which separate beads by magnetism instead of centrifugation.

In contrast, the difference in crosslinking/reversion efficiencies at genomic loci could not be reduced by leaving out the crosslinking because it is an essential part of the protocol. The incomplete reversion of crosslinking led to depletion of protein-rich chromosomal regions during DNA preparation (Fig. 5). If this depletion were similar in the IP and input DNA it would not appear as ChIP signal because the corresponding ratio would be one. However, different rates of depletion in IP and input DNA would let this ratio go up or down. If for example $60 \%$ of a crosslinked site is reversed in the IP DNA but only $30 \%$ in the input DNA this would appear as two-fold enrichment and potentially as false positive target. Thus, transcriptionally active regions of the chromosome are more likely to show a high background signal. This problem could not be solved by variation of reversion conditions (Table 1). However, as one way to better separate 
the real targets from such background we increased the specific signal by using the supernatant of the immunoprecipitation as input DNA. This should amplify the specific signal because it will be enriched in the immunoprecipitated DNA and at the same time reduced in the reference DNA.

A high background signal originating from nondigested RNA may also occur in ChIP-Chip experiments. This will for example be high if the Klenow fragment is used for labelling of immunoprecipitated DNA, since it can use RNA as primer to incorporate labelled nucleotides. If a linker-mediated PCR is used to amplify the immunoprecipitated DNA the amount of RNA relative to DNA will be reduced, potentially reducing the RNAcaused background. Here we show that a thorough RNase digestion is a suitable way to eliminate the RNA background, allowing a free choice of subsequent labelling and amplification techniques.

An additional origin of high background signals in microarray analysis is caused by the occurrence of nonunique sequences on the chromosomes. A systematic evaluation of labeling and microarray hybridization of predefined DNA targets revealed such genome redundancy as one major cause of false positives [12]. A probe to a non-unique sequence will bind a mix of DNA fragments originating from different chromosomal loci. The chromosomal position can influence the protein binding to the different copies of a non-unique sequence and may therefore lead to erroneous ChIP-Chip results. If for example one copy is located downstream an active promoter and the other copy not, a RNA polymerase ChIP would enrich the first locus but not the second. On the microarray this would appear as a medium enrichment at both chromosomal positions. Additional errors might occur at non-unique sequences with multiple copies and some sequence variation. In this case one probe might be complementary to for example two copies and the neighboring one to seven copies. Genes that are typically nonunique are the ribosomal and transfer RNA genes or transposons but also for example the rhs $A B C D$ gene family or gadAB in E. coli.

To estimate the degree of false positives caused by nonunique sequences we screened the literature for occurrence of the mentioned genes as target sites in microarray studies. Appearance of non-unique sequence false positives turned out to be quite frequent. For example, 36 out of 269 'extended protein occupancy domains' in a recent study from Vora et al. are in regions with non-unique sequences [13]. Some studies even draw major conclusions from the appearance of non-unique sequence false positives. For example, the heat shock regulator HspR was suggested to be involved in regulation of $t R N A$ and rRNA genes in Streptomyces coelicolor [14], the B. subtilis condensin SMC was proposed to be recruited to $r R N A$ and $t R N A$ genes [15] and $t R N A$ genes were described to be cohesin loading sites both in budding and fission yeast $[16,17]$. All of the mentioned gene loci are non-unique in the respective genomes. Note that in principle the described conclusions could be right; it is just that the results of microarray experiments can say nothing about it and might actually be misleading instead. Fortunately, non-unique sequences can be easily detected and corresponding probes be excluded from data sets. Even better would be elimination during array design.

Beside the causes of high background described in this study other factors have been shown to affect the background level. For example Lee and colleagues point out that ChIP-Chip experiments are highly dependent on the antibody used for the immunoprecipitation [4]. The background signal will be high if the antibody performs poorly or if it binds other proteins unspecifically. In this context the salt concentration of the IP and wash buffer is critical and can be adjusted to optimize immunoprecipitation [4]. In addition to the experimental procedure improper data processing can lead to false positive findings. How the data are analyzed will depend on different factors such as probe density and the relative number of binding sites [2]. Correct normalization regarding the dye bias in two color microarrays has been shown to be essential for ChIP-Chip experiments [18].

\section{How frequent are false positives in published ChIP-Chip data?}

The presence of non-unique sequence false positives might indicate that a high number of false positives are the rule, rather than exception in published ChIP-Chip studies. A false positive rate about $50 \%$ was found by our reinvestigation of a published $\sigma^{32}$-study [10]. The conclusion that the targets found in the published ChIP-Chip experiment but not in our study are false positives is supported by findings from others [11,19]. While almost all of the targets we detected have been found with other methods then ChIP-Chip, the only evidence for the supposed new targets by Wade et al. is their ChIP-Chip analysis $[10,11,19]$. It is noteworthy that this analysis was done with the protocol used in the first experiment of our study producing a high background [3]. In addition the supposed new targets lacked a typical $\sigma^{32}$-recognition site [10].

Further evidence for a frequent false-positive rate in ChIP-Chip studies comes from large differences of binding site detections in parallel studies. For example, FIS was found to bind all regions on the $E$. coli genome that are bound by RNA polymerase despite the absence of consensus binding sites [20]. A later study showed very different results with data that nicely fit the distribution of FIS binding motifs [21]. In two independent studies the binding of the estrogen receptor to the human chromo- 

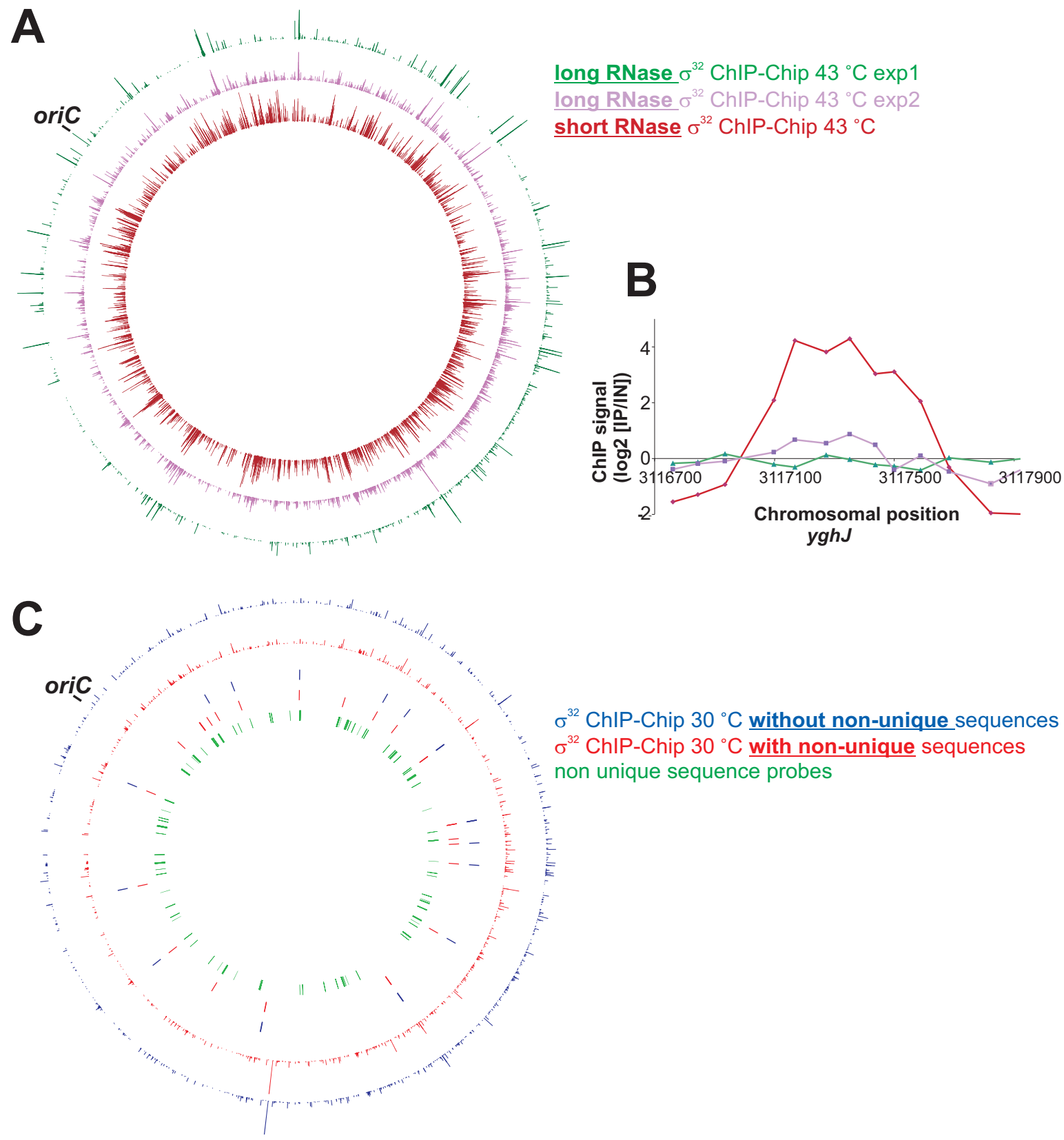

Figure 8 Non-unique sequences and limited digestion of RNA cause false positives in ChIP-Chip experiments. A $\sigma^{32}$ ChIP signal after long (two experiments, green and violet) and short RNase incubation (dark red). B $\sigma^{32}$ ChIP signal for the ygh J region (Colors are as in A). C $\sigma^{32}$ ChIP-Chip of E. coli grown at $30^{\circ} \mathrm{C}$ analyzed excluding non-unique sequences (blue) and including non-unique sequences (red). Inner three circles mark the position of peaks detected (similar coloring as for ChIP signals) and positions of non-unique sequences (green).

some 17 of MCF-7 breast cancer cells was analyzed $[22,23]$. We compared the 389 binding sites described in the Gevry study to the 390 sites detected in the Carroll study and found only about $50 \%$ overlap (binding sites were considered the same when not more than $2000 \mathrm{bp}$ apart, data not shown). Interestingly, others have also suggested an extended degree of false positives as expla- nation for contradictory results in parallel ChIP-Chip studies. Highly dissimilar binding patterns of the Mediator complex in yeast were reported [24-26]. Fan and Struhl reinvestigated the contradictory results and suggested that the differences were caused by a high degree of false positives due to the experimental set-up of Andrau and colleagues [27]. These supposed false posi- 
tives are mainly located in transcriptionally active coding regions as is also the case in our study.

A high number of false positives would make systematic approaches to analyze ChIP-Chip-derived binding sites especially difficult. Indeed, a recent analysis of yeast ChIP-Chip data revealed that only $48 \%$ of detected transcription factor binding sites could be explained by direct binding and an additional $16 \%$ by indirect binding [28]. The remaining $36 \%$ of the data set could not be explained by either direct or indirect transcription factor binding and were suggested to be noise. Taken together, high false positive rates seem to be common in ChIP-Chip studies. In some cases it actually seems to be an accepted fact. For example, Partridge and colleagues removed over one third of ChIP-Chip detected NsrR target sites just because they did not fit their expectations of lying in promoter regions [29]. However, this high false-positive rate was not investigated any further.

\section{How to deal with the background}

Beside the need for technical improvements, the high level of ChIP-Chip false positives emphasizes the great importance of suitable control experiments. Good controls are ChIP-Chip experiments with cells lacking the IP epitope (for instance $\Delta s e q A$; Fig. 6), mock IPs without antibody (Fig. 5A) or IPs with preimmune serum or IPs from cells growing under conditions that are expected to give no or reduced binding of the respective protein (such as $30^{\circ}$ for the heat shock sigma factor $\sigma^{32}$; Fig. $8 \mathrm{C}$ ). A suitable control experiment has two important functions. First, it allows estimation of the experimental quality. In this study the $\triangle s e q A$ control was the key to understanding that the ChIP-Chip method gave high background (Fig. 4 and 6). Second, a control experiment can help to detect targets in the actual experiment. We used the $\sigma^{32}$ control ChIP-Chip at $30^{\circ} \mathrm{C}$ to find significant targets in the corresponding data set of heat shocked cells (see materials and methods).

It has been suggested that DNA from control experiments should be used as a hybridization reference, meaning that for example the IP DNA from a $w t$ strain and a deletion strain are differentially labeled and hybridized to the same array [30]. However, others point out that a control should never be used as hybridization reference [2]. We agree with the latter opinion because use of control DNA as hybridization reference would not allow assessment of the experimental quality as outlined above. For instance, bad quality DNA from experiments with limited digestion of RNA (Fig. 8A-B) might not be detected if used as hybridization reference. Taken together, appropriate control experiments should be included in every ChIP-Chip study. Submission of the raw and processed control data to the public should be self-evident but is an exception in published studies so far.
Recently, chromatin immunoprecipitation has been combined with high throughput sequencing methods (ChIP-Seq). Interestingly, an analysis of different types of control DNA resulted in a variable pattern of background distributed over the chromosomes [31,32]. The pattern of background peaks varied between input DNA, noncrosslinked DNA and mock-IP DNA and lead to the conclusion that the type of reference DNA directly influence the number of sites deemed significant when scoring ChIP-Seq data. This underlines that the described problems apply to chromatin immunoprecipitation based methods in general.

\section{Revised ChIP-Chip method reveals new biological insights}

The revised ChIP-Chip method we developed enabled us to analyze binding of the sequestration protein SeqA to the $E$. coli chromosome. SeqA is involved in regulation of replication initiation and also proposed to play a role in chromosome organization and segregation [6]. It was found to exhibit prolonged binding to hemimethylated GATC sites at oriC and thereby hindering reinitiation $[7,33]$. Enhanced binding of SeqA at oriC was also found in our ChIP-Chip analysis, in fact it was the highest peak detected (Fig. 7). The second-highest peak was in the dnaA promoter region which has been shown to have an exceptionally long hemimethylation period [8]. While our data support SeqA binding as proposed for oriC and the dnaA promoter it contradicts published suggestions on chromosome-wide binding. Brendler and colleagues found an even distribution of potential SeqA binding sites over the chromosome [34]. Our data suggest that SeqA structures retain specific DNA tracts for varying amounts of time. Most striking is the relatively short duration of SeqA binding to the left and right of oriC and to the DNA at about one-quarter of the chromosome surrounding the replication terminus. The latter finding is in contrast to results from ChIP-PCR experiments with synchronized cells which suggested a prolonged SeqA binding in the terminus region [35]. Clearly, further analysis and additional experiments are needed to understand the biological meaning of the SeqA binding pattern.

\section{Conclusions}

We describe here a revised ChIP-Chip method and show its potential to greatly reduce false positive target site detection, which seems to be a widespread problem. Although we present many examples of high false positive rates in published studies, it has to be pointed out that this will vary greatly with the exact experimental details as outlined above. Since method details such as the duration of the RNase treatment or the use of spin columns have a major impact on the background signal, it is of high importance $t$ give an accurate description of the procedure used. The results reported here should allow 
critical reviewing of published ChIP-Chip studies as well as assessment and potential modification of other variants of the ChIP-Chip method and related methods.

\section{Methods \\ Cell growth, crosslinking and preparation of cell extracts}

For SeqA and RNA polymerase ChIP-Chip E. coli MG1655 or MG1655 $\Delta$ seqA (Table 5) was grown at $37^{\circ} \mathrm{C}$ to an $\mathrm{OD}_{600}$ of about 0.15 in $50 \mathrm{ml} \mathrm{LB}(+0.2 \%$ glucose $)$ before $27 \mu \mathrm{l}$ of formaldehyde (37\%) per ml medium were added (final concentration 1\%). Crosslinking was performed at slow shaking $(100 \mathrm{rpm})$ at room temperature for $20 \mathrm{~min}$ followed by quenching with $10 \mathrm{ml}$ of $2.5 \mathrm{M}$ glycine (final concentration $0.5 \mathrm{M}$ ). For heat-shock experiments, E. coli MG1655 was grown in $65 \mathrm{ml} \mathrm{LB}$ medium at $30^{\circ} \mathrm{C}$ to an $\mathrm{OD}_{600}$ of about 0.3 . Subsequently $30 \mathrm{ml}$ of culture was transferred to a pre warmed flask at $43^{\circ} \mathrm{C}$ and the remainder kept at $30^{\circ} \mathrm{C}$. Crosslinking and quenching was as described above except that cells were kept at 30 or $43^{\circ} \mathrm{C}$ for $5 \mathrm{~min}$ before further slow shaking at room temperature. Cells were collected by centrifugation and washed twice with cold TBS (pH7.5). After resuspension in $1 \mathrm{ml}$ lysis buffer (10 mM Tris (pH 8.0), 20\% sucrose, 50 $\mathrm{mM} \mathrm{NaCl}, 10 \mathrm{mM}$ EDTA, $10 \mathrm{mg} / \mathrm{ml}$ lysozyme) and incubation at $37^{\circ} \mathrm{C}$ for $30 \mathrm{~min}$ followed by addition of $4 \mathrm{ml}$ IP buffer, cells were sonicated on ice with 12 times $30 \mathrm{sec}$ and $30 \mathrm{sec}$ breaks at an UP $400 \mathrm{~s}$ Ultrasonic processor (Dr. Hielscher $\mathrm{GmbH}$ ) with $100 \%$ power. After centrifugation for $10 \mathrm{~min}$ at $9000 \mathrm{~g}, 800 \mu \mathrm{l}$ aliquotes of the supernatant were stored at $-20^{\circ} \mathrm{C}$.

\section{ChIP}

The ChIP protocol initially used in this study was as described in Grainger et al., 2004 except that DNA was purified with phenol/chloroform instead of a PCR clean up kit. $800 \mu \mathrm{l}$ of sonicated cell extract (see above) was incubated with $20 \mu \mathrm{l}$ protein A/G agarose beads (Ultralink) and $5 \mu$ of SeqA antiserum or antibody against RNA polymerase subunit $\beta$ (Neoclone) at $4^{\circ} \mathrm{C}$ over night. Samples were transferred to a Spin-X centrifuge column (Costar), centrifuged for $2 \mathrm{~min}$ at $4.000 \mathrm{rpm}$ to collect the beads. The flow through was removed. Washing was done by adding $500 \mu \mathrm{l}$ buffer to the beads on the spin column and rotation at room temperature for three minutes with subsequent collection of the beads by centrifugation as above. Washing was performed with the following buffers (IP buffer two times all others one time): IP buffer (50 mM HEPES-KOH pH 7.5, $150 \mathrm{mM} \mathrm{NaCl}, 1$ mM EDTA, $1 \%$ Triton $\times 100,0.1 \%$ Sodium deoxycholate, $0.1 \%$ SDS), IP buffer with $500 \mathrm{mM} \mathrm{NaCl}$, wash buffer $(10 \mathrm{mM}$ Tris pH 8.0, $250 \mathrm{mM} \mathrm{LiCl,} 1 \mathrm{mM}$ EDTA, 0.5\% Nonidet-P40, $0.5 \%$ Sodium deoxycholate) and TE. For elution, $100 \mu \mathrm{l}$ elution buffer (50 mM Tris (pH 7.5), $10 \mathrm{mM}$ EDTA, 1\%
SDS) was added to the column with the beads, incubated in a $65^{\circ} \mathrm{C}$ water bath for $10 \mathrm{~min}$ and centrifuged as above. To reverse the cross link $80 \mu \mathrm{l} \mathrm{TE}$ and $20 \mu$ proteinase $\mathrm{K}$ $(20 \mathrm{mg} / \mathrm{ml})$ were added and samples incubated for $2 \mathrm{~h}$ at 42 and $6 \mathrm{~h}$ at $65^{\circ} \mathrm{C}$. DNA was purified with phenol/chloroform. To prepare the control DNA, $800 \mu \mathrm{l}$ of sonicated cell extract was incubated at $65^{\circ} \mathrm{C}$ over night. $1 \mu \mathrm{l}$ RNase A $(20 \mathrm{mg} / \mathrm{ml})$ were added and samples incubated $30 \mathrm{~min}$ at $65^{\circ} \mathrm{C}$ before extraction with phenol/chloroform. The ChIP protocol as described above resulted in the high background signal (Fig. 2 and 4).

The following modifications were applied for the other ChIP-Chip experiments. First, agarose beads were not collected on a spin column but instead at the bottom of a usual $1.5 \mathrm{ml}$ eppendorf tube. The supernatant was then removed by pipetting. Second, the control DNA was taken from the supernatant resulting from centrifugation of the precipitated chromatin beads processed further as the immuno precipitated DNA after elution. Third, before addition of proteinase $\mathrm{K}$, sample and control DNA were incubated with RNase A $(50 \mu \mathrm{g} / \mathrm{ml})$ for at least 90 min at $42^{\circ} \mathrm{C}$ (except in the $\sigma^{32}$-analysis shown in Fig. 8A where incubation was $30 \mathrm{~min}$ as indicated). Incubation of

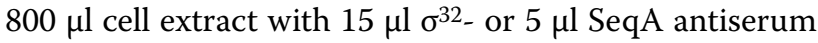
was for $1 \mathrm{~h}$ at $4^{\circ} \mathrm{C}$.

\section{Labeling and array hybridisation}

Usually DNA from six parallel immuno-precipitations (each with $800 \mu \mathrm{l}$ extract as described) were joined and labeled with Cy3-dCTP using the Klenow fragment and random primers of the BioPrime kit from Invitrogen. An equal amount of hybridization control DNA was labeled with Cy5-dCTP. Hybridization was for about $36 \mathrm{~h}$ at $55^{\circ} \mathrm{C}$ to $E$. coli whole genome microarrays from Oxford Gene Technology. The arrays have a probe length of 60 bases and a start to start spacing of about 150 bases. ChIP-Chip analysis were made in duplicates, except the crosslinkreversion array (Fig. 5), the $\Delta s e q A$ arrays (Fig. 6) and the shorter RNase incubation array (Fig. 8A). Please note that the array hybridized with the SeqA ChIP of the $\Delta s e q A$ strain with the unmodified method was of poor quality but regarded sufficient for its purpose described above.

\section{Microarray data processing}

Arrays were scanned on an Agilent SureScan High-Resolution Scanner. Spot intensities were extracted using the Feature Extraction software 10.5.1.1 from Applied Biosystems with a linear dye normalization correction method. The data were further analyzed with the statistics software $\mathrm{R}$, in particular the Bioconductor package and the limma library [36,37]. The background was subtracted and data points with a value below 0 after background subtraction were removed. Ratios of $\mathrm{g}$ (sample) to $\mathrm{r}$ (con- 
Table 5: Strains and oligonucleotides used in this study

\begin{tabular}{lll}
\hline Strain or oligonucleotide & Relevant characteristic(s) or sequence & Source or reference \\
\hline Strains & \\
\multicolumn{1}{c}{ E. coli MG1655 } & F- $\lambda$ rph-1 (wild type) & Guyer et al., 1981; Jensen, 1993 \\
\multicolumn{1}{c}{ MG1655 $\Delta$ seqA } & $\Delta$ seqA10 & Torheim et al., 2000 \\
Oligonucleotides & \\
uvrDfw & AGTTCCCGCAGGTGTTATC & \\
uvrDrv & GTCAGCGTCAGTTCTGCAT & \\
uvrDprobe & AGACGCCCGCCTTCATCCAG (5' FAM - 3' TAMRA) \\
yahEFfw & CCATCGAGACGATCAAAGAA & \\
yahEFrv & CAGCATCTGGCTTGTTGTT & \\
yahEFprobe & AACTCGCGTCCTTCGGCAGC (5' FAM - 3' TAMRA) \\
rpsDfw & AAGTTGATGCTGGCAAGATG & \\
rpsDrv & TAAAGCTCGACGATCAGGTG & \\
rpsDprobe & TCAGAACGCTCCGGCTTACGC (5' FAM - 3' TAMRA) \\
\hline
\end{tabular}

trol) were calculated and normalized to the array wide average. For arrays performed in duplicates the mean of the two normalized values was calculated. Probes in gene regions with non unique sequences were deleted (a list is available on request). For $\sigma^{32}$-target detection data obtained from heat-shocked cells were searched for two or more neighboring probes with a $\log _{2}$ signal $>0.5$ in both replicates. This resulted in 74 potential targets (34 previously described, 9 described exclusively by Wade et al., 2006, 31 not found by Wade et al.). After subtraction of $\log _{2}$ signals of the corresponding replicates from nonheat-shocked cells, 47 potential targets remained (Tables 2, 3, 4; 34 previously described, 7 described exclusively by Wade et al., 2006, 6 not found by Wade et al.). For peak detection in $\sigma^{32}$-data of non-heat-shocked cells (Fig. 8C) we searched for probes with a $\log _{2}$ ratio $>1$ and the one to the left and right $>0.5$.

GenomeViz was used for visualization of ChiP-Chip data [38]. Data points with $\log _{2}$ ratios $>0.5$ were extracted and the corresponding genome locus assigned as $1000 \mathrm{bp}$ up- and down-stream of the respective probe middle. For the moving window calculation of SeqA binding the sum of positive $\log _{2}$ ratios of 60.000 bp windows were calculated with a step size of 1000 bps. Raw as well as processed data are available at the Genome Omnibus Database, accession number GSE19053. To analyze the overlap of ChIP-Chip experiments a cut-off was chosen for each data set to select $\sim 1000$ probes with the highest ChIP signal (or the lowest signal for the crosslinking experiment). The overlap is the number of probes were the signal is beyond this cut-off at similar positions in the two compared data sets.

\section{ChIP washing comparison}

For the comparison of washing methods (Fig. 5A) $2 \times 800$ $\mu \mathrm{l}$ of crosslinked, sonicated MG1655 cell extract were incubated with $20 \mu \mathrm{l}$ protein $\mathrm{A} / \mathrm{G}$ agarose beads (Ultralink) without antibody for $1 \mathrm{~h}$ at $4^{\circ} \mathrm{C}$. One of these mock IP samples was then processed with the use of spin-columns and one without as described above. Eluted DNA was purified with phenol/chloroform and analysed by quantitative PCR as described below. Note that purification of the DNA with a Qiagen PCR cleanup kit gave the same results as the phenol extraction (data not shown).

\section{Crosslink comparison}

To compare crosslinked-reversed with non crosslinked DNA $100 \mathrm{ml}$ E. coli MG1655 LB culture was grown at $37^{\circ} \mathrm{C}$ to an $\mathrm{OD}_{600}$ of 0.15 . After collecting $50 \mathrm{ml}$ as 'non crosslinked' sample, crosslinking was done as described above. Crosslinked and non crosslinked cells were washed and sonicated corresponding to the ChIP-Chip protocol above. For experiments presented in Fig. 5B and $5 \mathrm{D}, 400 \mu \mathrm{l}$ of the sonicated extracts were mixed with 400 $\mu \mathrm{l}$ TE and incubated with $2 \mu \mathrm{l}$ RNase A $(20 \mathrm{mg} / \mathrm{ml})$ at $42^{\circ} \mathrm{C}$ for $1 \mathrm{~h}$. Next, $200 \mu \mathrm{l}$ proteinase $\mathrm{K}(20 \mathrm{mg} / \mathrm{ml})$ were added and samples incubated for $2 \mathrm{~h}$ at 42 and $6 \mathrm{~h}$ at $65^{\circ} \mathrm{C}$. For experiments without proteinase $\mathrm{K}$ shown in table 1, $200 \mu \mathrm{l}$ of crosslinked extract was mixed with 200 $\mu \mathrm{TE}$ and incubated at $65^{\circ} \mathrm{C}$ over night or $10 \mathrm{~min}$ at $100^{\circ} \mathrm{C}$. For the other experiments $200 \mu \mathrm{l}$ were mixed with $160 \mu \mathrm{TE}$ plus $40 \mu \mathrm{l}$ proteinase $\mathrm{K}(20 \mathrm{mg} / \mathrm{ml})$ and incubated at $37^{\circ} \mathrm{C}$ over night or for $2 \mathrm{~h}$ at $42^{\circ} \mathrm{C}$ followed by $65^{\circ} \mathrm{C}$ for $6 \mathrm{~h}$. DNA was extracted with phenol and chlorophorm and analyzed by microarray hybridization (as above) or qPCR as described below. 


\section{Quantitative RT PCR}

Reactions were carried out in triplicates of $25 \mu$ volume each. About $10 \mathrm{ng}$ DNA was used as template in $10 \mu \mathrm{l}$ $\mathrm{ddH}_{2} \mathrm{O}$ and added to a mix of 12.5 TaqMan Gene Expression mix (Applied Biosystems) and $2.5 \mu \mathrm{l}$ primer mix (9 $\mu \mathrm{M}$ each forward and reverse primer and $2.5 \mu \mathrm{M}$ probe) in 96 well PCR plates. For a primer list see Table 5. Reactions were carried out with a 7500 Real Time PCR System (Applied Biosystems). The system software was used to calculate $\mathrm{Ct}$ values which were transformed to relative values of template DNA. qPCR values for the $y a h E F$ gene region were used for normalization.

\begin{abstract}
Abbreviations
ChIP-Chip: chromatin immunoprecipitation combined with microarrays; ChIPSeq: chromatin immunoprecipitation combined with next generation sequencing; IP: immunoprecipitation.
\end{abstract}

\section{Authors' contributions}

TW designed and carried out the experiments, analyzed the data and drafted the manuscript. KS participated in design of the study, interpretation of data and in writing of the manuscript. Both authors read and approved the final manuscript.

\section{Acknowledgements}

We thank Franz Narberhaus (Bochum) for the $\sigma^{32}$ antiserum and Douglas Hurd (Oxford Gene Technology) for instruction in DNA labeling and microarray hybridization. We are grateful for the support from the Helse Sør-Øst/University of Oslo Microarray Core Facility, supported by the functional genomics programme (FUGE) of the Research Council of Norway. We thank Erik Boye, Frank Führer and Leonardo A. Meza-Zepeda for critical reading of the manuscript and the Skarstad-group for helpful discussions. Irene Kim is acknowledged for her help with submission of the microarray data to the Genome Omnibus Database. Supported by the Norwegian Research Council FUGE program and the German Research Foundation (WA 2713/1-1).

\section{Author Details}

Department of Cell Biology, Institute for Cancer Research, The Norwegian Radium Hospital, Oslo University Hospital and University of Oslo, 0310 Oslo, Norway

Received: 9 February 2010 Accepted: 5 July 2010

Published: 5 July 2010

\section{References}

1. Ren B, Robert F, Wyrick JJ, Aparicio O, Jennings EG, Simon I, Zeitlinger J, Schreiber J, Hannett N, Kanin E, et al.: Genome-wide location and function of DNA binding proteins. Science 2000, 290(5500):2306-2309.

2. Buck MJ, Lieb JD: ChIP-chip: considerations for the design, analysis, and application of genome-wide chromatin immunoprecipitation experiments. Genomics 2004, 83(3):349-360.

3. Grainger DC, Overton TW, Reppas N, Wade JT, Tamai E, Hobman JL, Constantinidou C, Struhl K, Church G, Busby SJ: Genomic studies with Escherichia coli MelR protein: applications of chromatin immunoprecipitation and microarrays. J Bacterio/ 2004, 186(20):6938-6943

4. Lee TI, Johnstone SE, Young RA: Chromatin immunoprecipitation and microarray-based analysis of protein location. Nat Protoc 2006, 1(2):729-748.

5. Sandmann T, Jakobsen JS, Furlong EE: ChIP-on-chip protocol for genome-wide analysis of transcription factor binding in Drosophila melanogaster embryos. Nat Protoc 2006, 1(6):2839-2855.

6. Waldminghaus T, Skarstad K: The Escherichia coli SeqA protein. Plasmid 2009, 61(3):141-150.

7. Slater S, Wold S, Lu M, Boye E, Skarstad K, Kleckner N: E. coli SeqA protein binds oriC in two different methyl-modulated reactions appropriate to its roles in DNA replication initiation and origin sequestration. Cell 1995, 82(6):927-936.

8. Campbell JL, Kleckner N: E. coli oriC and the dnaA gene promoter are sequestered from dam methyltransferase following the passage of the chromosomal replication fork. Cell 1990, 62(5):967-979.

9. Nagy PL, Cleary ML, Brown PO, Lieb JD: Genomewide demarcation of RNA polymerase II transcription units revealed by physical fractionation of chromatin. P Natl Acad Sci USA 2003, 100(11):6364-6369.

10. Wade JT, Roa DC, Grainger DC, Hurd D, Busby SJ, Struhl K, Nudler E: Extensive functional overlap between sigma factors in Escherichia coli. Nat Struct Biol 2006, 13(9):806-814.

11. Nonaka G, Blankschien M, Herman C, Gross CA, Rhodius VA: Regulon and promoter analysis of the $E$. coli heat-shock factor, $\sigma^{32}$, reveals a multifaceted cellular response to heat stress. Genes Dev 2006, 20(13):1776-1789.

12. Johnson DS, Li W, Gordon DB, Bhattacharjee A, Curry B, Ghosh J, Brizuela L, Carroll JS, Brown M, Flicek P, et al.: Systematic evaluation of variability in ChIP-chip experiments using predefined DNA targets. Genome Res 2008, 18(3):393-403

13. Vora T, Hottes AK, Tavazoie S: Protein occupancy landscape of a bacterial genome. Mol Cell 2009, 35(2):247-253.

14. Bucca G, Laing E, Mersinias V, Allenby N, Hurd D, Holdstock J, Brenner V, Harrison M, Smith CP: Development and application of versatile high density microarrays for genome-wide analysis of Streptomyces coelicolor: characterization of the HspR regulon. Genome Biol 2009, 10(1):R5.

15. Gruber S, Errington J: Recruitment of condensin to replication origin regions by $\mathrm{ParB} / \mathrm{SpoOJ}$ promotes chromosome segregation in $B$. subtilis. Cell 2009, 137(4):685-696.

16. D'Ambrosio C, Schmidt CK, Katou Y, Kelly G, Itoh T, Shirahige K, Uhlmann F: Identification of cis-acting sites for condensin loading onto budding yeast chromosomes. Genes Dev 2008, 22(16):2215-2227.

17. Schmidt CK, Brookes N, Uhlmann F: Conserved features of cohesin binding along fission yeast chromosomes. Genome Biol 2009, 10(5):R52.

18. Peng S, Alekseyenko AA, Larschan E, Kuroda MI, Park PJ: Normalization and experimental design for ChIP-chip data. BMC Bioinformatics 2007, 8:219.

19. Zhao K, Liu M, Burgess RR: The global transcriptional response of Escherichia coli to induced $\sigma^{32}$ protein involves $\sigma^{32}$ regulon activation followed by inactivation and degradation of $\sigma^{32}$ in vivo. J Biol Chem 2005, 280(18):17758-17768.

20. Grainger DC, Hurd D, Goldberg MD, Busby SJ: Association of nucleoid proteins with coding and non-coding segments of the Escherichia coli genome. Nucleic Acids Res 2006, 34(16):4642-4652.

21. Cho BK, Knight EM, Barrett CL, Palsson BO: Genome-wide analysis of Fis binding in Escherichia coli indicates a causative role for A-/AT-tracts. Genome Res 2008, 18(6):900-910.

22. Carroll JS, Meyer CA, Song J, Li W, Geistlinger TR, Eeckhoute J, Brodsky AS, Keeton EK, Fertuck KC, Hall GF, et al.: Genome-wide analysis of estrogen receptor binding sites. Nat Gen 2006, 38(11):1289-1297.

23. Gevry N, Hardy S, Jacques PE, Laflamme L, Svotelis A, Robert F, Gaudreau $\mathrm{L}$ : Histone H2A.Z is essential for estrogen receptor signaling. Genes Dev 2009, 23(13):1522-1533.

24. Andrau JC, van de Pasch L, Lijnzaad P, Bijma T, Koerkamp MG, van de Peppel J, Werner M, Holstege FC: Genome-wide location of the coactivator mediator: Binding without activation and transient Cdk8 interaction on DNA. Mol Cell 2006, 22(2):179-192.

25. Fan X, Chou DM, Struhl K: Activator-specific recruitment of Mediator in vivo. Nat Struct Mol Biol 2006, 13(2):117-120.

26. Zhu X, Wiren M, Sinha I, Rasmussen NN, Linder T, Holmberg S, Ekwall K, Gustafsson CM: Genome-wide occupancy profile of mediator and the Srb8-11 module reveals interactions with coding regions. Mo/ Cell 2006, 22(2):169-178

27. Fan X, Struhl K: Where does mediator bind in vivo? PLOS ONE 2009, 4(4):e5029.

28. Gordan R, Hartemink AJ, Bulyk ML: Distinguishing direct versus indirect transcription factor-DNA interactions. Genome Res 2009, 19(11):2090-100.

29. Partridge JD, Bodenmiller DM, Humphrys MS, Spiro S: NsrR targets in the Escherichia coli genome: new insights into DNA sequence 
requirements for binding and a role for $\mathrm{NsrR}$ in the regulation of motility. Mol Microbiol 2009, 73(4):680-94.

30. Efromovich S, Grainger D, Bodenmiller D, Spiro S: Genome-wide identification of binding sites for the nitric oxide-sensitive transcriptional regulator NsrR. Methods Enzymol 2008, 437:211-233.

31. Auerbach RK, Euskirchen G, Rozowsky J, Lamarre-Vincent N, Moqtaderi Z, Lefrancois P, Struhl K, Gerstein M, Snyder M: Mapping accessible chromatin regions using Sono-Seq. Proc Natl Acad Sci USA 2009, 106(35):14926-14931.

32. Lefrancois P, Euskirchen GM, Auerbach RK, Rozowsky J, Gibson T, Yellman CM, Gerstein M, Snyder M: Efficient yeast ChIP-Seq using multiplex short-read DNA sequencing. BMC Genomics 2009, 10:37.

33. Lu M, Campbell JL, Boye E, Kleckner N: SeqA: a negative modulator of replication initiation in E. coli. Cell 1994, 77(3):413-426.

34. Brendler T, Sawitzke J, Sergueev K, Austin S: A case for sliding SeqA tracts at anchored replication forks during Escherichia coli chromosome replication and segregation. EMBO J 2000, 19(22):6249-6258.

35. Yamazoe M, Adachi S, Kanaya S, Ohsumi K, Hiraga S: Sequential binding of SeqA protein to nascent DNA segments at replication forks in synchronized cultures of Escherichia coli. Mol Microbiol 2005, 55(1):289-298

36. Gentleman RC, Carey VJ, Bates DM, Bolstad B, Dettling M, Dudoit S, Ellis B, Gautier L, Ge Y, Gentry J, et al.: Bioconductor: open software development for computational biology and bioinformatics. Genome Biol 2004, 5(10):R80.

37. Smyth GK, Speed T: Normalization of cDNA microarray data. Methods 2003, 31(4):265-273.

38. Ghai R, Hain T, Chakraborty T: GenomeViz: visualizing microbial genomes. BMC Bioinformatics 2004, 5:198.

Submit your next manuscript to BioMed Central and take full advantage of:

- Convenient online submission

- Thorough peer review

- No space constraints or color figure charges

- Immediate publication on acceptance

- Inclusion in PubMed, CAS, Scopus and Google Scholar

- Research which is freely available for redistribution

Submit your manuscript at www.biomedcentral.com/submit
Ciomed Central 